\title{
Revista
}

HOSPITALIDADE

ISSN 1807-975X

Volume 14, n.01, Agosto de 2017

\section{EVENTOS CULTURAIS: MEU DINHEIRO ME DIZ AONDE VOU? Uma análise sob a ótica da Teoria da Identidade Social (SIT)}

Sâmara Borges Macedo ${ }^{1}$

Marlusa de Sevilha Gosling ${ }^{2}$

Danielle Carolina de Queiroz ${ }^{3}$

\section{RESUMO}

O trabalho objetivou investigar o acesso, e a experiência, em eventos culturais, pagos e gratuitos, sob a ótica dos participantes, e compará-los. Para tanto, foram realizadas entrevistas semiestruturadas em profundidade com dois grupos distintos, um de evento pago e um de evento gratuito obtendo-se uma amostra de 20 respondentes, de acordo com o critério estabelecido por Minayo (1992), sendo 10 de um evento pago, realizado em Inhotim, e 10 de um evento gratuito, realizado em comunidades de baixa renda, chamado Descontorno Cultural. A metodologia utilizada é a qualitativa, com tipologia descritivo-exploratória. Os dados foram tratados por meio da análise de conteúdo de Bardin (2011), com categorias pré-definidas baseadas nas três vertentes da Teoria da Identidade Social (SIT), defendida por Vinarean (2013): categorização social, identificação social e comparação social. Os resultados indicaram que o acesso a eventos está relacionado ao poder aquisitivo e à consequente possibilidade de pagá-lo. No entanto, sob a ótica da SIT, há similaridade entre as razões sociais para participação, independentemente da gratuidade ou não do evento.

Palavras-chave: eventos culturais; análise de conteúdo; teoria da identidade social (SIT).

\footnotetext{
ABSTRACT

The objective of this study was to investigate the access, and the experience, in cultural events, paid and free, from the perspective of the participants, and to compare them. In order to do so, we conducted semi-structured interviews in depth with two distinct groups, one of paid event and

${ }^{1}$ Doutoranda da UFMG- Universidade Federal de Minas Gerais. Email: samaraborgesmacedo@outlook.com

${ }^{2}$ Professora Associada de Marketing da Universidade Federal de Minas Gerais. Email: mg.ufmg@gmail.com

${ }^{3}$ Mestranda da UFMG- Universidade Federal de Minas Gerais. Email: danielle.cqueiroz@gmail.com
} 
one of free event, obtaining a sample of 20 respondents, according to the criterion established by Minayo (1992), 10 being a paid event, held in Inhotim, and 10 of a free event held in low-income communities called Cultural Disorder. The methodology used is qualitative with descriptiveexploratory typology. The data were treated through the content analysis of Bardin (2011), with pre-defined categories based on the three aspects of the Social Identity Theory (SIT) defended by Vinarean (2013): social categorization, social identification and social comparison. The results indicated that access to events is related to purchasing power and the consequent possibility of paying it. However, from the point of view of SIT, there is a similarity between the social reasons for independent participation of the event or not.

Key-words: cultural events; content analysis; Social identity theory (SIT).

\section{RESUMEN}

El trabajo tuvo como objetivo investigar el acceso, y la experiencia, en eventos culturales, pagados y gratuitos, bajo la óptica de los participantes, y compararlos. Para ello, se realizaron entrevistas semiestructuradas en profundidad con dos grupos distintos, uno de evento pagado y uno de evento gratuito obteniéndose una muestra de 20 respondedores, de acuerdo con el criterio establecido por Minayo (1992), siendo 10 de un evento pagado , realizado en Inhotim, y 10 de un evento gratuito, realizado en comunidades de bajos ingresos, llamado Descontorno Cultural. La metodología utilizada es cualitativa con el tipo descriptivo y exploratorio. Los datos se analizaron mediante análisis de contenido de Bardin (2011), con categorías predefinidas en base a tres aspectos de la Teoría de la Identidad Social (SIT) defendido por Vinarean (2013): categorización social, la identidad social y la comparación social. Los resultados indicaron que el acceso a los eventos se relaciona con el poder adquisitivo y la consiguiente capacidad de pagarlo. Sin embargo, desde la perspectiva de la ITE, existe una similitud entre las razones sociales para la participación independiente de la gratuidad o no del evento.

Palabras clave: eventos culturales; análisis de contenido; la teoría de la identidad social (SIT).

\section{1- INTRODUÇÃO}

A vida em sociedade permite às gerações passarem os símbolos, práticas sociais e comportamentos para as gerações seguintes, compreendendo então, dentro das Ciências Sociais, esse conjunto a ser passado como a cultura (CHAUí, 1997). Ainda segundo a autora, a mesma é 
transmitida e influenciada pela sociedade da qual o indivíduo faça parte. Dentro da cultura, temse o patrimônio cultural que, segundo Guia (2008), evolui e se cria ao longo do tempo e das interações.

Uma forma de manifestação da cultura são os eventos. O mercado brasileiro de eventos gera cerca de 7,5 milhões de empregos, desse total, quase $80 \%$ dos eventos são voltados à cultura (ABEOC, 2013). Os eventos dinamizam a Economia, trazendo benefícios, principalmente, para o local de realização (HIXSON, 2014).

No entanto, o acesso a eventos culturais, e à cultura em si, ainda é considerado privilégio de classes sociais mais abastadas, haja vista que o acesso à cultura é relacionado ao capital financeiro e intelectual do indivíduo, há tempos. Como exemplo, têm-se os estudos de Bourdieu (1979), que analisou a distinção entre os gostos das diferentes classes sociais e, em 1983, relacionou a classe social mais alta com maior acesso ao Capital Cultural (CC) (BOURDIEU, 1983). Holt (1998) relacionou três tipos de CC as classes. Em contrapartida, ao se observar o crescente número de trabalhos voltados ao estudo da temática em classes mais baixas, e em periferias e favelas (DA FONSECA, 2014 ; GOLÇALVEZ; PEREIRA, 2015; AMOROSO (2015); DEL MONTE (2015); GU; ZHANG (2015); SANTIAGO, 2016; PEREZ; PRZYBYLSKI (2016); MACHADO (2016)), compreende-se haver uma tendência 'à mudança do padrão até então estabelecido.

Considerando a representatividade dos eventos culturais e a possibilidade de mudança no acesso à cultura, o presente trabalho teve, por objetivo, investigar o acesso e a experiência em eventos culturais, pagos e gratuitos, sob a ótica dos participantes, e compará-los entre si tendo como embasamento a Teoria da Identidade Social (SIT) e as três vertentes da mesma: categorização social, identificação social e comparação social, defendidas por Vinarean (2013).

Os autores Chiang et al. (2016) acreditam que a SIT ainda é pouco utilizada para compreensão do comportamento de participantes em eventos. Assim sendo, tal constatação justifica a realização desse estudo e busca contribuir para a robustez da temática.

O trabalho apresenta a seguinte estrutura: a introdução, seguida por um referencial teórico, em que são trabalhados os temas; eventos culturais e acesso à cultura. Em seguida, são apresentados os procedimentos metodológicos, os resultados e discussões, considerações finais, findando-se com as referências utilizadas. 


\section{2- REFERENCIAL TEÓRICO}

\subsection{Eventos culturais}

Segundo a Associação Brasileira de Empresas de Eventos, em uma pesquisa denominada II Dimensionamento Econômico da Indústria de Eventos no Brasil de 2013, o mercado de eventos gera 7,5 milhões de empregos, em cerca de 590 mil eventos em todo o país. Destes eventos, 78,7\% são eventos socioculturais (ABEOC, 2013).

Para Falassi (1987), evento é um fenômeno social dinâmico, encontrado em todas as sociedades do mundo. Eventos são importantes para fomentar o turismo tornando-se pontos fortes para as campanhas de marketing nesse setor (GERTZ, 2008; HIXSON, 2014; LIU, 2014), tornando-se, desde a segunda metade do século XX, importantes dentro da indústria turística (GETZ, 2010).

Os eventos também podem criar uma oportunidade de lazer e recreação para o mercado local e regional (LIU, 2014). Trazem contribuições econômicas para o local e, por isso, governantes e organizações de marketing, têm interesse em capitalizar todo o impacto positivo por eles trazido (HIXSON, 2014). Rollins e Delamere (2007) acrescentam ao mencionado, a representação considerável que os eventos possuem para o desenvolvimento de diversos setores, como cultura, artes, turismo.

Eventos podem apresentar temas distintos como esportes, turismo, recreação e lazer. Esse caráter plural gera dificuldades de entendimento do setor (HASSANIEN ; DALE, 2013). Gertz (2008) corrobora ao afirmar que a pluralidade dos eventos permite discussões sobre fenômenos sociais, culturais, ambientais e econômicos.

O estudo de eventos, como uma disciplina, começou no início dos anos 2000 (GERTZ, 2008). Kim, Boo e Kim (2013) realizaram uma pesquisa para revisar a bibliografia sobre eventos e chegaram à conclusão que estava dividida em seis áreas: administração e estratégia, pesquisa e desenvolvimento, finanças, controle e operações, marketing, e gestão de recursos humanos. Para os autores, há um número pequeno de artigos que discutem questões relativas a participação de turistas em festivais, apesar do aumento gradual de pesquisas relacionadas a atitude, motivação, comportamento e satisfação de turistas. Há uma grande atenção de estudos focados em analisar não só questões econômicas, mas também outros aspectos como; sociais, culturais e ambientais (ANDERSON ; LUNDBERG, 2013). 

Teoria da Identidade Social (SIT). Revista Hospitalidade. São Paulo, volume 1, n.01, p. 01-23, agosto de 2017.

Getz e Page (2015), ao estudarem o turismo de eventos, relacionaram os eventos à Teoria das Necessidades de Maslow, defendendo que os mesmos atendem a realização da necessidade de cada nível (fisiológico, de segurança, de amor e pertencimento, e auto-realização).

Aos eventos são relacionadas diversas razões de atração e participação. Um dos respondentes da pesquisa de Soria, Blanco-Romero e Valiente, (2014) ressalta que festivais não atraem apenas pela música, mas também pelo ambiente e toda a sua construção. Nesse sentido, a socialização é um fator relevante para a participação de visitantes em festivais (SHANKA ; ALAMIYO, 2012). O aspecto social é um fator importante pois, ao criar um espaço público, permite que visitantes e comunidade possam conviver e se familiarizar, uns com os outros. Atualmente, há uma atenção maior dos pesquisadores sobre esse assunto (JEPSON; CLARKE ; RAGSDELL, 2014). O envolvimento das pessoas nativas em eventos também chama a atenção de visitantes (GERTZ, 2008).

Como os motivos para a participação em eventos são diferentes, a experiência dos visitantes também não é a mesma. Tais motivos podem variar de acordo com o papel que o indivíduo desempenha no festival (HIXSON, 2014).

Chiang et al. (2016) investigaram festivais e eventos como reuniões sociais. Para isso, os autores aplicaram a Teoria da Identidade Social (SIT), que acreditam ter sido pouco utilizada para analisar (ou pesquisar) o comportamento de participantes de eventos. A utilização da referida teoria é defendida também por Chalip (2006). A SIT é relacionada a atividades em grupo (LIU; LÁSZLÓ, 2007; HORNSEY, 2008), tratando da perspectiva que o indivíduo tem sobre a participação, bem como as relações intergrupais e afiliações sociais (YUKI, 2003).

Vinarean (2013) a aborda sob três vertentes: categorização social, identificação social e comparação social. A primeira vertente diz respeito à categorização que os indivíduos fazem uns dos outros, baseados nas características dos grupos aos quais pertencem, podendo ocorrer uma auto categorização (HORNSEY, 2008). As categorizações podem ser baseadas na educação, cultura, política, variando de acordo com cada contexto (LEE et al. 2010; VINEREAN, 2013). A identificação social ocorre quando há sentimento de pertencimento a um grupo (BAGOZZI; DHOLAKIA, 2006), uma identidade social (OYSERMAN; ELMORE ; SMITH, 2012). Grappi e Montanari (2011) atribuem a chance de revisitação a festivais à essa segunda vertente da SIT. A terceira vertente trata a comparação social, fenômeno que ocorre quando os membros de um grupo se comparam a outro, podendo gerar uma autoestima positiva (BLANTON; MILLER, 
2000) ou uma autoestima negativa, conforme exposto por Haferkamp e Krämer (2011), Van Houtte, Demanet e Stevens (2012). Boo, Carruthers e Busser (2014) a denominam como baixa estima e acreditam que a mesma reduz a intenção de visitação em eventos. Em contrapartida, Jaeger e Mykletn (2013) acreditam que os eventos podem remodelar a autoestima, ou seja, transformá-la positivamente.

\subsection{Acesso à cultura}

Usar a educação como meio de desenvolvimento de respeito, entendimento e preservação do patrimônio cultural, é imprescindível, segundo Souza e Santos (2014). Nesse sentido, torna-se mister considerar o modo como o conhecimento é absorvido pelos consumidores, à medida que isso influencia diretamente em como o indivíduo se enxerga e se sente parte de um patrimônio cultural. Os autores defendem, ainda, que o incentivo à integração, e a interação cultural estimula o interesse em conservação da cultura. Além disso, fatores sociais, econômicos, e políticos devem ser, também, considerados nesse contexto (SOUZA; SANTOS, 2014).

Congruente com isso, têm-se a visão de Bourdieu, que, em seus estudos, buscou compreender como o Capital Cultural (CC) influencia os gostos e preferências, e o acesso à cultura e educação, de diferentes classes. Para o autor, os gostos estão associados diretamente à classe social, pela possibilidade de acesso que ela proporciona aos indivíduos. Em outras palavras, classes sociais mais altas, possuem mais facilidade de acesso à cultura e desenvolvem gostos mais refinados, enquanto que as classes mais baixas, dadas suas condições, possuem menos acesso, portanto, possuem gostos menos refinados. Definem-se, então, segundo o autor, diferentes preferências segundo as classes; populares, classe média e classe dominante (BOURDIEU, 1979).

Holt (1998) definiu o Capital Cultural sob três perspectivas, sendo elas: Capital Cultural Incorporado, Capital Cultural Objetivado e Capital Cultural Institucionalizado. Sendo o primeiro considerado como aquele que poderá influenciar as escolhas profissionais e culturais do indivíduo, uma vez que é considerado como o capital adquirido e moldado no seio familiar, tornando-se parte integrante da pessoa. O Capital Cultural Objetivado é o voltado ao acesso e escolhas por livros, viagens, filmes, etc., entendendo-se como aquele representado pelo consumo, ou seja, como o que o indivíduo escolhe consumir como forma de expressão da cultura. Assim sendo, o segundo Capital definido por Holt(1998), está diretamente relacionado ao primeiro, haja 
MACEDO,S.B.; GOSLING, M. S.; QUEIROZ D. C. Eventos Culturais: meu dinheiro me diz aonde eu vou? Uma análise sob a ótica da Teoria da Identidade Social (SIT). Revista Hospitalidade. São Paulo, volume 1, n.01, p. 01-23, agosto de 2017.

vista que os gostos adquiridos no decorrer da vida influenciarão as escolhas do indivíduo (HOLT, 1998).

O terceiro, o Capital Cultural Institucionalizado, é aquele adquirido por meio do estudo formal, em cursos, nas escolas. Nesse sentido, de acordo com o autor, e com o defendido por Bourdieu (1983), as classes mais altas, por terem maior poder aquisitivo, tendem a apresentar maior Capital Cultural Institucionalizado.

A orientação à cultura tem-se mostrado um tema que tem ganho interesse na área acadêmica, como pode ser observado pelos diversos estudos sobre a temática, como, por exemplo: Bonamino; Alves e Franco (2010), Dunt; Hage, e Kelaher (2010), Oliveira e Melo-Silva (2010), Formiga (2011, 2013 e 2016), Formiga e Diniz (2012), Bihari (2013), Lata (2013), Eslami, Sahrapeyma e Abotalebi (2013), Macedo (2014), Schori; Hofmann e Abel (2014), Centeno (2015), Wu (2015), Leite (2016), Leavitt (2016), Lewis (2017).

Alguns desses estudos, como os de Bihari (2013) e Macedo (2014), confirmam a relação do Capital Cultural maior a um poder aquisitivo mais alto, e maior acesso à cultura.

Apesar de o acesso à cultura ser muito relacionado a um maior poder aquisitivo e alto Capital Cultural, nota-se um interesse de pesquisadoras em investigar o contrário, ou seja, o acesso à cultura pelas classes menos abastadas. Como exemplo, tem-se o trabalho de Freitas e Siman (2015), que estudaram museus de periferias e favelas. Pode-se observar vários estudos voltados à cultura de favelas (DA FONSECA, 2014 ; GOLÇALVEZ; PEREIRA, 2015; AMOROSO (2015); DEL MONTE (2015); GU; ZHANG (2015); SANTIAGO, 2016; PEREZ; PRZYBYLSKI (2016); MACHADO (2016).

\section{3- PROCEDIMENTOS METODOLÓGICOS}

Visando atender o objetivo proposto, a abordagem do presente trabalho é denominada qualitativa, pois, de acordo com Yin (2011), é responsável pela interpretação e análise dos significados dos fenômenos e por buscar maior entendimento sobre uma temática (BAUER; GASKELL, 2007). O estudo possui tipologia descritivo-exploratória à medida que busca explorar mais profundamente um tema e descrever as características de um grupo (MALHOTRA, 2006).

Para investigar o acesso e a experiência em eventos culturais, pagos e gratuitos, sob a ótica dos participantes e compará-los entre si, foram realizadas entrevistas semiestruturadas, em 
MACEDO,S.B.; GOSLING, M. S.; QUEIROZ D. C. Eventos Culturais: meu dinheiro me diz aonde eu vou? Uma análise sob a ótica da Teoria da Identidade Social (SIT). Revista Hospitalidade. São Paulo, volume 1, n.01, p. 01-23, agosto de 2017.

profundidade, com esses dois grupos distintos. Obteve-se, então, um conjunto de 20 respondentes, sendo 10 participantes de um evento pago, e 10 de um evento gratuito, realizado em comunidades de baixa renda. O critério utilizado para a definição da quantidade de respondentes foi o de saturação, defendido por Minayo (1992), em que as entrevistas são realizadas até haver incidência de respostas semelhantes, não acrescentando assim algo novo. A escolha dos entrevistados se deu de forma aleatória e espontânea, ou seja, foram entrevistados aqueles que, abordados, optaram por conceder a entrevista.

Um grupo de respondentes foi abordado em Inhotim, que segundo informações do site oficial, é uma OSCIP (Organização da Sociedade Civil de Interesse Público) que possui acervos de arte contemporânea do mundo, e uma coleção botânica, que reúne espécies raras de todos os continentes, e fica localizada a $60 \mathrm{~km}$ de Belo Horizonte, na cidade de Brumadinho (MG) (INHOTIM, 2016). A coleta de dados foi realizada no dia 10 de setembro de 2016, dia em que foi realizado um dos eventos de comemoração aos 10 anos de Inhotim, contando com o show da cantora nacionalmente conhecida, Marisa Monte, além da possibilidade de visitação ao parque como um todo. Foi um evento pago com o valor inicial do ingresso de $\mathrm{R} \$ 150,00$.

O segundo grupo de respondentes foi abordado em um evento chamado Descontorno Cultural, festival cultural gratuito, realizado em 16 centros culturais da Fundação Municipal de Cultura da Cidade de Belo Horizonte, e no Centro de Referência da Cultura Popular e Tradicional Lagoa do Nado. Segundo informações do site de relacionamento oficial do evento, bem como com o site oficial do estado de Minas Gerais, o evento visou expressar a cultura local, oferendo 12 horas de atividades diversas (oficinas, apresentações artísticas, exposições, linguagens artísticas, circo, teatro, dança, música, literatura, artes visuais e cultura popular, dentre outros) a locais em que a cultura é pouco acessada (DESCONTORNO, 2016; BELO HORIZONTE, 2016).

A coleta no referido evento se deu no dia 03 de setembro de 2016, data da realização do mesmo. As entrevistas foram realizadas mediante autorização dos idealizadores do evento e ocorreram no Centro Cultural Jardim Guanabara, um dos 17 pontos de realização, durante as 12 horas de atividades.

O roteiro de entrevista é apresentado no Quadro 1. A questão 5 do roteiro foi adaptada a cada evento. 
MACEDO,S.B.; GOSLING, M. S.; QUEIROZ D. C. Eventos Culturais: meu dinheiro me diz aonde eu vou? Uma análise sob a ótica da

\section{Quadro 1- Roteiro de Entrevista}

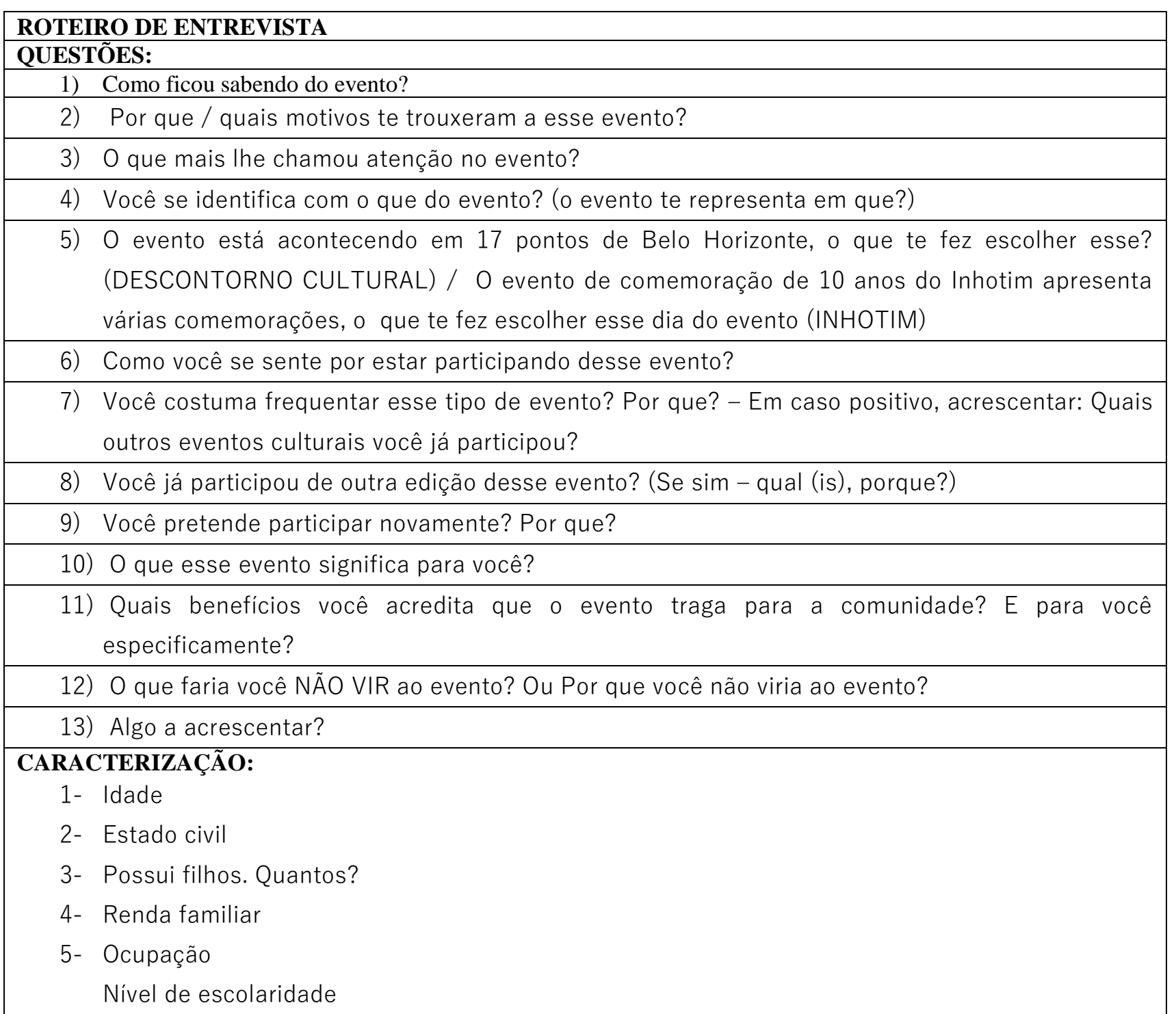

Fonte: Elaborado pelas autoras, 2017

\subsection{Instrumento de Pesquisa e análise dos dados}

Optou-se pela utilização da Análise de Conteúdo de Bardin (2011) como técnica e análise dos dados.

Para tanto, conforme explicitado, foram realizadas entrevistas semiestruturadas, que foram gravadas e transcritas. Seguiu-se então os três polos cronológicos propostos por Bardin (2011): 1) pré análise, na qual, após definido o corpus do trabalho, e transcritas as entrevistas, foram marcados os pontos de destaque de cada entrevista relacionados ao referencial e mais relevantes em cada entrevistas transcritas (evento pago e evento gratuito). No segundo polo, definido pela 
autora como exploração do material, foram analisadas as marcações, agrupadas de acordo com a semelhança, analisadas de acordo com o referencial. Nesse momento, a releitura tornou-se imprescindível. Agruparam-se, então, as marcações de acordo com as subcategorias prédefinidas, considerando as três vertentes da Teoria da Identidade Social (SIT) defendida por Vinarean (2013): categorização social, identificação social e comparação social.

O terceiro polo trata das inferências, interpretações e analises dos resultados, que serão apresentados no próximo tópico.

\section{4- RESULTADOS E DISCUSSÕES}

Inicialmente serão apresentadas as análises de cada núcleo para, posteriormente realizar-se a comparação entre eles.

\subsection{Análise de Conteúdo}

Conforme explicitado nos procedimentos metodológicos, a análise de conteúdo foi realizada segundo Bardin (2011) e optou-se por utilizar categorias pré-definidas baseadas no referencial do presente estudo. As categorias escolhidas foram as defendidas por Vinarem (2013) como as três vertentes da Teoria da Identidade Social (SIT): categorização social, identificação social e comparação social.

As análises foram realizadas inicialmente em separado, ou seja, primeiro realizou-se a AC do evento em Inhotim, em seguida realizou-se a AC do evento Descontorno Cultural, para posteriormente realizar as considerações sobre os dois eventos.

As transcrições apresentadas no decorrer do tópico foram transcritas literalmente, ou seja, com vícios de linguagem e pausas, e os entrevistados foram referenciados por meio de números visando resguardar a identidade dos mesmos.

\subsection{Caracterização dos respondentes do evento em Inhotim}

Esse grupo foi composto por 10 respondentes, desses, 8 do sexo feminino e 2 do sexo masculino. Indicando uma maior abertura a participação da pesquisa por parte desse gênero, não representando necessariamente, maior participação do gênero em questão no evento.

Todos os respondentes possuiam curso superior concluído. Em relação à média da renda familiar mensal, os valores variaram de 4 salários mínimos a 17,5 salários mínimos, sendo esse último valor atribuído somente por um respondente. Portanto, excluindo tal valor por ser único e discrepante, a média da renda familiar mensal foi de 6 salários mínimos (considerando o valor 
do salário mínimo de 2016), indicando congruência com o defendido por Holt (1998) e Macedo (2014) no que tange a maior facilidade de acesso à cultura por indivíduos com maior CC e classe social mais alta (BORDIEU, 1983).

Todos os respondentes moram em cidades vizinhas a Brumadinho (Belo Horizonte, Betim, Contagem, Divinópolis).

\subsubsection{Análise de Conteúdo das entrevistas realizadas no evento em Inhotim}

\subsubsection{Categoria 1: Categorização Social}

Nessa categoria considerou-se a categorização social como a classificação que os indivíduos fazem uns dos outros, bem como de si mesmo, baseando-se nas características dos grupos aos quais pertencem (HORNSEY, 2008).

Os resultados foram evidentes e correlatos à medida que apresentaram uma mesma tendência. Os respondentes compreenderam os participantes do evento, bem como eles mesmos, como pessoas abertas e interessadas em cultura e natureza, e acreditam que o Inhotim possibilite a congruência das duas coisas (cultura e natureza) em um único local: "isso representa um evento que eu consigo congregar natureza, com arte, com pessoas interessantes “ (ENTREVISTADO 7). O exposto vai ao encontro do estudo de Soria, Blanco-Romero e Valiente (2014), quando tratam da atratividade dos eventos como uma construção do ambiente como um todo, aliando tanto música, como ambiente.

Os respondentes definiram-se também como pessoas privilegiadas, como uma parcela da população que consegue ter acesso a cultura: "Me sinto muito privilegiada por participar, principalmente por conseguir comprar" (ENTREVISTADO 1). Outro exemplo, é o da Entrevistada 7: "Me sinto privilegiada, o valor é muito alto. Sei que não é todo mundo que pode estar aqui, então me sinto privilegiada".

Nota-se que essa última categorização realizada pelos respondentes foi voltada à condição financeira e de acesso à cultura, bem como afirmaram Lee et al. (2010) e Vinerean (2013), sobre os diferentes pontos que podem basear a categorização e relaciona-se também a Bihari (2013) e Macedo (2014) quanto à relação maior poder aquisitivo, maior acesso à cultura.

\subsubsection{Categoria 2: Identificação Social}


Essa categoria foi a mais frequente em todas as entrevistas realizadas em Inhotim. Todos os entrevistados apresentaram notória identificação com o evento, com o local e com a atmosfera do mesmo.

"Eu me identifico muito com a natureza aqui. A vontade de andar descalço. De ficar à vontade. Eu gosto muito de natureza" (ENTREVISTADO 10).

“O evento me traz identificação porque eu gosto muito da Marisa Monte, é ao ar livre, então essas coisas combinam muito comigo" (ENTREVISTADO 4).

O sentimento de pertencimento a um grupo (BAGOZZI; DHOLAKIA, 2006) é confirmado por meio das transcrições dos entrevistados:

"combinamos entre amigas, compramos os ingressos juntas e viemos. Essas foram as maiores motivações" (ENTREVISTADO 10).

“O que me traz identificação aqui é o contato com a natureza, é um momento de sentar com amigos. Porque quem vem pra cá geralmente vem com família, com amigos, então favorece muito esse "vamos estar juntos" (ENTREVISTADO 6).

"Eu não vim para o evento pensando em um benefício para mim mesmo, mas para meu grupo" (ENTREVISTADO 3).

Os relatos acima além de confirmarem o exposto por Bagozzi e Dholakia (2006) e de Oyserman, Elmore e Smith (2012), no que tange a identidade social, convergem com Getz e Page (2015). Os autores relacionaram eventos planejados à Teoria das Necessidades de Maslow, uma vez que acreditam que os eventos atendam aos níveis da pirâmide proposta. Entende-se aqui, que o evento supriu o nível que aborda a necessidade de amor e pertencimento, e mais ainda, o de auto realização: “Um evento como esse me traz bem-estar ... É um benefício difícil de nomear, é uma sensação de bem-estar e prazer" (ENTREVISTADO 2).

"Eu me sinto muito relaxado por estar aqui, feliz também" (ENTREVISTADO 4).

"Eu sinto muita paz, alegria e plenitude de estar aqui. Assim...uma realização" (ENTREVISTADO 9).

A chance de revisitação atribuída a Identificação Social por Grappi e Montanari (2011), também ficou clara, demonstrando assim quão considerável é a influência social na escolha de evento (SHANKA; ALAMIYO, 2012). A exemplo, têm-se o relato do Entrevistado 10: "quero poder voltar para conhecer Inhotim melhor, porque o nosso foco hoje é o evento mesmo". 


\subsubsection{Categoria 3: Comparação Social}

A comparação social ocorre quando os membros de um grupo se comparam a outro grupo, podendo implicar em auto estima alta (BLANTON; MILLER, 2000) ou baixa estima (BOO; CARRUTHERS; BUSSER, 2014).

Nesse sentido, a presente categoria mistura-se a categorização social, em que os respondentes, ao se classificarem, comentaram e classificaram os outros indivíduos presentes no evento também. Assim sendo, a classificação foi de similaridade, ou seja, defenderam que as pessoas do evento eram parecidas e estavam no local buscando as mesmas coisas, inferindo-se então que, esse evento estimulou a auto estima, uma vez que os participantes sentiram-se bem por estarem ali com outros indivíduos com características similares

Alguns respondentes definiram-se como privilegiados, uma vez que tiveram condições financeiras para participar do evento, reconhecendo que muitas pessoas não as tem. Ao se classificarem como privilegiados, reconhecem a existência de um grupo de desprivilegiados, na sociedade.

“A comunidade também deve ficar na expectativa. Uma parte desse evento deveria ser aberto a comunidade" (ENTREVISTADO 8).

"Me sinto privilegiada, o valor é muito alto. Sei que não é todo mundo que pode estar aqui, então me sinto privilegiada" (ENTREVSTADO 2).

\section{3 - Caracterização dos respondentes do evento Descontorno Cultural}

O grupo foi composto por 10 respondentes, sendo 6 do sexo feminino, e 4 do sexo masculino. A idade variou de 12 a 66 anos, o que não permitiu a análise pela média de idade, mas que demonstrou a diversidade do público. Como as entrevistas foram realizadas no local, foi possível notar que havia desde crianças de colo até idosos. Tal fato pode ser atribuído a diversidade de atrações que ocorreram durante as 12 horas do evento.

Os valores relacionados à renda familiar mensal, variaram de um salário mínimo a 10, sendo esse último atribuído somente por um respondente. Portanto, excluindo tal valor, a média da renda familiar mensal foi de 2,6 salários mínimos (considerando o valor do salário mínimo de 2016).

A maioria dos respondentes possui ensino médio completo (7), dois respondentes possuem ensino fundamental incompleto e somente uma respondente possui pós-graduação.

Todos os respondentes são membros da comunidade local em questão. 


\subsubsection{Análise de Conteúdo das entrevistas realizadas no evento Descontorno Cultural}

A análise de conteúdo foi realizada considerando como categorias pré-definidas inicialmente as três vertentes da SIT, conforme exposto. No entanto, ao proceder com a AC desse evento, notou-se um padrão de resposta recorrente e que não se encaixava diretamente em nenhuma das três categorias pré-definidas.

Assim sendo, optou-se por criar uma subcategoria dentro da categoria 3 (Comparação Social), a qual recebeu o nome de Papel Social. Tal procedimento é indicado por Bardin (2011).

\subsubsection{Categoria 1: Categorização Social}

Nessa primeira categoria buscou-se identificar como os respondentes classificavam a si mesmos e os demais grupos presentes.

Os respondentes, em geral identificaram-se como pessoas que apreciam a arte e cultura:

"Eu sou um cara da arte, que ama a arte" (ENTREVISTADO 1).

As respostas foram congruentes com o defendido por Lee et al. (2010) e Vinerean (2013). Os autores afirmam que a categorização pode se dar baseada em perspectivas diversas como política, cultura, etc., sendo baseada de acordo com o contexto em questão. Os respondentes classificaram esse apreço pela arte e cultura baseados em atividades diferentes como música (hip hop e rap), grafite, teatro e dança. Ou seja, cada respondente atribuiu identificação com um tipo de atividade ocorrida durante as 12 horas de evento. Nota-se então, que a categorização indica relação direta com a identificação social. Em outras palavras, a pessoa se define por meio daquilo que ela realmente gosta e a representa.

A categorização sobre outros grupos (HORNSEY, 2008), não ficou evidente nas entrevistas, isso provavelmente devido ao fato de que grande parte dos presentes serem da comunidade, e, por conviverem, compartilharem gostos semelhantes. Assim, a categorização social pode ser considerada uniforme no que tange a auto categorização e a categorização de terceiros.

\subsubsection{Categoria 2: Identificação Social}

Sobre o sentimento de pertencimento a um grupo (BAGOZZI; DHOLAKIA, 2006) e uma identidade social (OYSERMAN; ELMORE; SMITH, 2012), ficou claro, em todas as entrevistas, 
que os respondentes se sentem parte do evento, identificando-se com vários pontos e até mesmo com tudo do evento segundo quatro entrevistados.

“isso aqui é o meu estilo de vida”. (ENTREVISTADO 6)

“significa união, porque tá todo mundo feliz, junto, mostrando trabalho, então é o principal”. (ENTREVISTADO 5)

"me identifico com a mensagem do evento". (ENTREVISTADO 7)

Notou-se também relação com o defendido por Getz e Page (2015) sobre a relação da Pirâmide Maslow e eventos. Nos relatos ficou evidente o atendimento ao degrau da pirâmide que trata das necessidades de afiliação, pertencimento e aceitação social:

"eu me sinto satisfeito demais, é gostoso conviver com outras pessoas" (ENTREVISTADO $3)$.

“o pessoal é muito gente boa, a gente faz amizades aqui" (ENTREVISTADO 8)

Ainda sobre a relação defendida por Getz e Page (2015), nota-se o que compreende a realização pessoal:

“ eu me sinto muito bem, é maravilhoso estar aqui” (ENTREVISTADO 2).

"é um evento que eu gosto, são em eventos desse tipo que me sinto bem, quem sou" (ENTREVISTADO 2)

" me sinto contagiada e satisfeita. Aqui você se diverte, esquece de tudo lá de fora, eu amo estar aqui”" (ENTREVISTADO 10).

\subsubsection{Categoria 3: Comparação Social}

Conforme exposto, a comparação social ocorre quando há a comparação de membros de um grupo em relação a outro, podendo gerar auto estima (BLANTON; MILLER, 2000) ou a baixa estima (BOO; CARRUTHERS; BUSSER,2014).

Assim, ao proceder com as análises das entrevistas do evento em questão, foi possível constatar similaridade nas respostas, sendo elas, tendenciosas a uma segregação. Os respondentes compreendem-se como membros da comunidade, e como membros coesos, compartilham gostos específicos, característicos a eles. Com isso, diferenciam-se claramente de membros de outras áreas da cidade.

“a galera que se reúne aqui é toda uma galera mais de periferia, só que é uma galera mais para esse lado (cultural)" ( ENTREVISTADO 2). 
“ como Descontorno Cultural o próprio nome diz né, sai do centro sul e vem para perto de nós da periferia” (ENTREVISTADO 5).

“ o evento permite mostrar uma imagem diferente nossa... porque o pessoal, as vezes, acha que a gente aqui é tudo parado, que não tem nada disso, que não gosta disso (evento cultural)" (ENTREVISTADO 7)

Os relatos ligam-se a questões relativas a estima elevada e baixa. O sentimento de desprezo externalizado por eles em relação a imagem que outros nichos da sociedade fazem deles (membros da periferia), poder-se-ia inferir que implicaria em baixa auto estima, como afirmado por Haferkamp e Krämer (2011), Van Houtte, Demanet e Stevens (2012) e Boo, Carruthers e Busser (2014). No entanto, ao prosseguir com as análises foi possível constatar que a união da comunidade, refletida no evento implica em uma remodelação da auto estima conforme defendem Jaeger e Mykletn (2013).

Ao comentarem sobre o evento, as respostas emergidas apresentaram padrões significativos, os quais foram classificados na subcategoria Papel Social.

\subsection{Subcategoria : Papel Social}

Optou-se por criar uma subcategoria dentro da categoria comparação social, pois, ao discorrerem sobre o evento, todos os entrevistados enfatizaram o papel social significativo que o evento tem para eles bem como para toda a comunidade.

Para Souza e Santos (2014), a educação é essencial como ferramenta de compreensão e preservação da cultura. O defendido pelos autores foi corroborado por meio das análises das entrevistas.

Os respondentes acreditam que eventos como esse realizado na comunidade, tem o poder de mudar a realidade social local, pois provém entretenimento, cultura, ocupação e ofício, o que implica em jovens trabalhando para o bem, longe de drogas e de violência.

“aqui é uma coisa bacana, as mensagens que passam...eles falam sobre cultura, política, machismo, sobre assuntos que a gente precisa discutir" (ENTREVISTADO 3) 
" aqui abre portas, olha o tanto de gente que veio, ainda mais com essa criançada que tá ai crescendo nesse mundo....ai pode mostrar um pouco da nossa cultura para eles" (ENTREVISTADO 4)

" a cultura faz as pessoas pensarem de alguma forma, como acontece, como é aplicada na comunidade carente... as pessoas precisam de algum movimento para pensarem de outra forma" (ENTREVISTADO 5)

" muitas pessoas que estavam no mundo das drogas, ao invés de estarem lá, estão aquil" (ENTREVISTADO 6)

“oferece entretenimento para os jovens, para não entrarem nesse mundo de drogas, de vida louca, para não fazerem coisas erradas" (ENTREVISTADO 9)

"ajuda o pessoal a ter mais consciência, principalmente a questão da política, que é o que mais precisa ultimamente. Tem as pessoas trocando ideias, tendo mais cultura né" (ENTREVISTADO 10)

Ao considerar os relatos infere-se que o contexto social influencia a valorização do evento cultural, uma vez que o mesmo contribui para com toda a comunidade, havendo, assim, interesse em preservar, ampliar e melhorar o evento. O exposto é congruente, mais uma vez, com o defendido por Souza e Santos (2014), ao abordar que a integração e interação estimula o interesse em conservação de um bem cultural.

"o evento tem que expandir, ele é muito interessante. Quanto mais gente atingir, mais mentes para abrir" (ENTREVISTADO 10)

Outro ponto a se considerar é a possibilidade de implicação social e econômica gerada pelo evento, assim como definido (ou exposto) em Hixson (2014).

\subsection{Análise de conteúdo dos eventos em Inhotim e Descontorno Cultural}

Após a realização das análises de cada evento, separadamente, buscou-se fazer a análise em conjunto, ou seja, buscou-se pontos divergentes e convergentes, possibilitando a comparação entre um evento pago e um gratuito. 
O evento Descontorno Cultural visa levar cultura à comunidades, carentes desse tipo de atividade, assim, ao considerar o objetivo do evento, bem como o perfil dos respondentes, o exposto contraria o defendido por Bourdieu (1983) pois o autor defende que classes mais altas possuem gostos mais refinados enquanto classes baixas, dadas suas condições e dificuldade de acesso à cultura, possuem gostos menos refinados. Com isso nota-se que o acesso à cultura demonstra propiciar uma mudança nesse quesito, possibilitando o questionamento do afirmado por Bourdieu (1983).

A supracitada observação pode contrapor o exposto por (BIHARI, 2013; MACEDO, 2014) que defendem que além do CC mais alto, o poder aquisitivo mais alto propicia maior acesso à cultura.

No entanto, nesse ponto cabe uma ressalva, o evento Descontorno cultural é um evento gratuito, aberto a toda comunidade, nesse sentido, não houve um investimento financeiro por parte dos presentes no evento. O que gera dúvida quanto a presença dos indivíduos no evento se o mesmo fosse pago.

Em contrapartida, todos os respondentes do evento realizado em Inhotim, apresentam pelo menos curso superior concluído, e possuem renda mensal média de 6 salários mínimos, o que indica congruência com o defendido por Holt (1998) e Macedo (2014) no que tange a maior facilidade de acesso à cultura por indivíduos com maior CC e classe social mais alta (BORDIEU, 1983).

Ao comparar os dois eventos estudados, nota-se que no evento realizado em Inhotim foi pago e o valor cobrado foi considerado alto pelos próprios participantes. Relacionado a isso têm-se o perfil dos presentes (nível de escolaridade e renda mais altos), contrapondo o perfil encontrado no Descontorno Cultural (nível de escolaridade e renda mais baixos).

Infere-se que no que tange aos gostos é possível notar uma mudança, ou seja, a classe social parece não ditar mais refinamento ou não quanto à cultura, ou seja, a classe social mais alta não implicará necessariamente em gostos mais refinados e a baixa em gostos menos refinados. No entanto, a condição financeira ainda se mostra um limitador quanto ao acesso à cultura, haja vista que no evento gratuito havia membros da comunidade local, e, no pago, a grande parcela era composta por indivíduos com maior poder aquisitivo.

Ficaram notórios os benefícios trazidos por eventos culturais, independente do caráter de gratuidade ou não, reafirmando questões já estudadas, como a identificação social 
(OYSERMAN; ELMORE; SMITH, 2012), o sentimento de pertença (BAGOZZI; DHOLAKIA, 2006), a melhora na auto estima (BLANTON; MILLER, 2000). No caso específico dos respondentes do Descontorno Cultural foi possível observar ainda a remodelação da autoestima conforme defendido por Jaeger e Mykletn (2013).

\section{5- CONSIDERAÇÕES FINAIS}

O trabalho teve por objetivo investigar o acesso e a experiência em eventos culturais pagos e gratuitos sob a ótica dos participantes e compará-los tendo como embasamento a Teoria da Identidade Social (SIT). Nesse sentido, o objetivo proposto foi atingindo uma vez que os dados analisados levaram as conclusões de que o acesso a eventos está relacionado ao poder aquisitivo e à consequente possibilidade de pagá-lo. Assim, ainda há uma segregação, ou seja, em eventos pagos, o número de participantes com maior poder aquisitivo ainda é alto, enquanto em eventos voltados a periferia, a maior parte dos participantes é composta por membros da própria comunidade.

Em relação à experiência em eventos, notou-se que independentemente do caráter do evento (gratuito ou pago) o grupo social estimula a participação, ou seja, perfis e gostos semelhantes motivam a participação bem como a troca e a vivência com o grupo de afinidades.

Os respondentes de ambos os eventos se definem baseados em outros núcleos e segregamse.

A principal diferença encontrada ainda é a questão financeira como determinante do tipo de evento o qual o indivíduo participará ou não, pois quanto aos objetivos, todos os respondentes buscavam cultura, entretenimento, convívio social.

Como contribuição gerencial, têm-se a possibilidade do uso das informações obtidas na pesquisa por parte de órgãos públicos e particulares. Sendo o fator financeiro ainda considerado um limitante para o acesso à cultura, cabe a órgãos governamentais atentar-se a essa questão repensando os tipos de eventos oferecidos a população, cabe também as instituições privadas estimularem a participação de diferentes classes aos eventos. Sugere-se que estudos quantitativos sejam feitos e que sejam investigados outros eventos. 


\section{REFERÊNCIAS}

ABEOC- II Dimensionamento Econômico da Indústria de Eventos no Brasil de 2013. Disponível em: http://www.abeoc.org.br/wp-content/uploads/2014/10/II-dimensionamento-setor-eventosabeoc-sebrae-171014.pdf. Acesso em: jan/2017.

AMOROSO, M. Quando a literatura política sobe o morro: grupos de oposição, favelas e cultura a partir da análise de um livro sobre o Borel. Antíteses, v. 8, n. 15, p. 154-175, 2015.

ANDERSSON, T. D.; LUNDBERG E. Commensurability and sustainability: Triple impact assessments of a tourism event. Tourism Management, 37 p. 99-109, 2013.

BAGOZZI, R. P.; DHOLAKIA, U. M. Antecedents and purchase consequences of customer participation in small group brand communities. International Journal of Research in Marketing, 23(1), 45-61, 2006.

BARDIN, L. Análise de conteúdo. Lisboa: Edições 70, 2011.

BAUER, M. W.; GASKELL, G. Qualitative research with text, image and sound. Vozes, Petrópolis, 2007.

BELO HORIZONTE. Pagina oficial de eventos culturais. Disponível em: http://www.belohorizonte.mg.gov.br/evento/2016/09/festival-descontorno-cultural-2016.

Acesso: set/2016.

BIHARI, S. Cultural capital and school success. International Journal of Research in Sociology and Social Anthropology, New York, v. 1, n. 1, p. 33-38, 2013.

BLANTON, H.; MILLER, D. T. The effects of in-group versus out-group social comparison on self-esteem in the context of a negative stereotype. Journal of Experimental Social Psychology, 36, 519-530, 2000.

BONAMINO, A. et al. The effects of the different forms of capital on school performance: a study illuminated by Bourdieu and Coleman. Revista Brasileira de Educação, Rio de Janeiro, v. 15, n. 45, p. 487-499, 2010.

BOO, S.; CARRUTHERS, C. P.; BUSSER, J. A. The constraints experienced and negotiation strategies attempted by nonparticipants of a festival event. Journal of Travel \& Tourism Marketing, 31(2), 269-285, 2014.

BOURDIEU, P. Algumas propriedades dos campos. In: BOURDIEU, P. Questões de sociologia. Rio de Janeiro: Marco Zero, p. 89-94, 1983.

BOURDIEU, P. La distinction. Paris: Les Éditions de Minuit, 1979.

CENTENO, M. J. As organizações culturais no espaço público. Contributos da comunicação organizacional. Interfaces da comunicação com a cultura, 2015.

CHALIP, L. Towards social leverage of sport events. Journal of Sport \& Tourism, 11(2), 109 127, 2006.

CHAUI, M. Convite à filosofia. 9. ed. São Paulo: Ática, 1997

CHIANG, L. et al. Investigating festivals and events as social gatherings: the application of social identity theory. Journal of Travel \& Tourism Marketing, p. 1-14, 2016.

DA FONSECA, C. F. Gestos, fabricações e cartografias políticas da cidade: sobre os projetos Solos Culturais e Guia Cultural de Favelas. Lugar Comum-Estudos de Mídia, Cultura e Democracia Universidade Federal do Rio de Janeiro. Laboratório Território e ComunicaçãoLABTeC/ESS/UFRJ-Vol 1, n. 43-maio-ago, p. 51, 2014. 
DE SOUZA, A. H. V.; DOS SANTOS, V. R. Educação para o patrimônio: mediação cultural na perspectiva dos museus e bibliotecas: uma experiência intersisciplinar na ciência da informação. Múltiplos Olhares em Ciência da Informação-ISSN 2237-6658, v. 2, n. 2, 2014. DEL MONTE, P. Of degrees and villas: writing and reading testimonios of high school graduates from a shanty town in Buenos Aires in their attempts to access and succeed in post-compulsory education studies. Tese de Doutorado. UCL Institute of Education, 2015.

DESCONTORNO CULTURAL. Pagina da rede social oficial do evento. Disponível em; https://www.facebook.com/descontornocultural/?fref=ts. Acesso: set/2016.

DIAZ S., I.; BLANCO-ROMERO, A.; VALIENTE, G.C.I. Emporda music festivals as tourism diversification tools, International Journal of Event and Festival Management, Vol. 5 No. 3, pp. 297-310, 2014.

DUNT, D.; HAGE, B.; KELAHER, M. The impact of social and cultural capital variables on parental rating of child health in Australia. Health Promotion International, Oxford, v. 26, n. 3, p. 290-301, 2010.

ESLAMI, S.; SAHRAPEYMA, M.; ABOTALEBI, N. Investigation the relationship between objectified cultural capital of parents with academic achievement of high school students.

Researcher, Washington, v. 5, n. 12, p. 91-96, 2013.

FALASSI, A. Time Out of Time: Essays on the Festival. Albuquerque: University of New Mexico, 1987.

FORMIGA, N. S. Proposta de um modelo parcimonioso entre a empatia e orientação cultural em brasileiros. Salud \& Sociedad: investigaciones en psicologia de la salud y psicologia social, v. 4, n. 2, p. 186-199, 2013.

FORMIGA, N. S. Verificação de um modelo teórico entre a empatia, socialização ética e orientação cultural em jovens brasileiros. Actualidades en Psicología, v. 30, n. 120, p. 99-114, 2016.

FORMIGA, N. S. Teste empírico de um modelo teórico entre o estilo de orientação cultural e as condutas desviantes em jovens de diferentes contextos sócio-escolares. Psicologia Argumento, v. 30, n. 69, p. 369-377, 2012.

FORMIGA, N. S.; DINIZ, A. da S.. Estilo da orientação cultural e condutas desviantes: Testagem de um modelo teórico. Psicologia em Pesquisa, v. 5, n. 1, p. 02-11, 2011.

FREITAS, K. A.; DE CASTRO S. L. M.. O museu dos quilombos e favelas urbanos no movimento da democratização dos museus. Dossiê: Gestão, Educação e Patrimônio Cultural, v. 7, n. 2, p. 116-120, 2015.

GERTZ, D. Event tourism: Definition, evolution, and research. Tourism Management, v. 29 (3), 403-428, 2008.

GETZ, D. The nature and scope of festival studies. International Journal of Event Management Research, v. 5, n. 1, 2010.

GETZ, D.; PAGE, S. J. Progress in Tourism Management Progress and prospects for event tourism research. Tourism Management 30, 1-39, 2015.

GONÇALVES, R. D.; PEREIRA, J. R. F.. O hip hop e a favela: reflexões sobre a história e cultura afro-brasileira e africana na sala de aula. Identidade, Diversidade e Alteridades, $p$.

234, 2015. 
MACEDO,S.B.; GOSLING, M. S.; QUEIROZ D. C. Eventos Culturais: meu dinheiro me diz aonde eu vou? Uma análise sob a ótica da Teoria da Identidade Social (SIT). Revista Hospitalidade. São Paulo,

GRAPPI, S.; MONTANARI, F. The role of social identification and hedonism in affecting tourist re-patronizing behaviours: The case of an Italian festival. Tourism Management, 32(5), 11281140, 2011.

GU, D. Z.; ZHANG, J. Landscape Renovation of Shantytowns in Industrial and Mining Cities Based on Social Psychology-In the Case of Copper Mining Shantytown of Tongling in Anhui Province. In: Advanced Materials Research. Trans Tech Publications, p. 1508-1518, 2015.

GUIA, A. T. B. A Valoração econômica de Bens Culturais: Uma aplicação a monumentos da cidade de Tomar. Dissertação (Mestrado em Economia das Organizações) - Programa de Mestrado em Economia das Organizações da Universidade de Trás-os-Montes e Alto Douro. Portugal, Vila Real, 2008.

HAFERKAMP, N.; KRÄMER, N. C. Social comparison 2.0: Examining the effects of online profiles on social-networking sites. Cyberpsychology, Behavior, and Social Networking, 14(5), 309-314, 2011.

HASSANIEN, A.; DALE, C. Toward a typology of events venues, International Journal of Event and Festival Management, Vol. 2 Iss 2 pp. 106 - 116, 2011.

HIXSON, E. The impact of young people's participation in events: developing a model of social event impact, International Journal of Event and Festival Management, Vol. 5 No. 3, pp. 198-218, 2014.

HOLT, D. Does cultural capital structure American Consumption? Journal of Consumer Research, Gainesville, v. 25, n. 1, p. 1-25, jun. 1998.

HORNSEY, M. J. Social identity theory and self-categorization theory: A historical review. Social and Personality Psychology Compass, v. 2, n. 1, p. 204-222, 2008.

JAEGER, K. ; MYKLETUN, R. J. Festivals, identities, and belonging. Event Management, 17(3), 213-226, 2013.

JEPSON, A.; CLARKE, A.; RAGSDELL, G. Integrating "self-efficacy" theory to the Motivation Opportunity - Ability (MOA) model to reveal factors that influence inclusive engagement within local community festivals, International Journal of Event and Festival Management, Vol. 5 Iss 3 pp. 219 - 234, 2014.

KIM, J.; BOO, S., KIM, Y. Patterns and trends in event tourism study topics over 30 years, International Journal of Event and Festival Management, Vol. 4 Iss 1 pp. 66 - 83, 2013.

LATA, L. N. Cultural capital and higher education in Bangladesh. International Review of Modern Sociology, v. 39, n. 2, 2013.

LEAVITT, P. The Effects of Student Social Class on Learning in Computer-Mediated Versus Face-to-Face Settings. The University of Arizona. 2016.

LEE, J. S.; LEE, C. K. ; CHOI, Y. Examining the role of emotional and functional values in festival evaluation. Journal of Travel Research, 50(6), 685-696, 2010.

LEITE, M I. O serviço educativo dos museus e o espaço imaginativo das crianças. Pro-Posições, v. 15, n. 1, p. 121-127, 2016.

LEWIS, A. D. Social Class and Race in the Classroom. In: Preservice Teachers, Social Class, and Race in Urban Schools. Palgrave Macmillan US, p. 11-22, 2017.

LIU, J. H.; LÁSZLÓ, J. A narrative theory of history and identity: Social identity, social representations, society and the individual. In G. Moloney e I. Walker (Eds.), Social representations and history. New York, NY: PalgraveMacmillan press, 2007.

LIU, Y. Cultural Events and Cultural Tourism Development: Lessons from the European Capitals of Culture, European Planning Studies, v. 22, n. 3, p. 498-514, 2014. 
MACEDO, S. B. As dimensões do consumo da nova classe média e a influência do capital cultural. Ufla 2014.

MACHADO, Mônica. Imaginários sociais sobre as favelas cariocas: o turismo-cultural do museu de favela e seus modos de ativação digital. Diálogo com a Economia Criativa, v. 1, n. 1, p. 6174, 2016.

MALHOTRA, N. K. Pesquisa de marketing: uma orientação aplicada. 4. ed. Porto Alegre: Bookman, 2006.

MINAYO, M. C. S. Ciência, técnica e arte: o desafio da pesquisa social. In: MINAYO, M. C. S. (Org.). Pesquisa social: teoria, método e criatividade. Petrópolis: Vozes, p. 09-29, 2001.

OLIVEIRA, M. D.; MELO-SILVA, L. L. Estudantes universitários: a influência das variáveis socioeconômicas e culturais na carreira. Revista Semestral da Associação Brasileira de Psicologia Escolar e Educacional, São Paulo, v. 14, n. 1, p. 23-34, 2010.

OYSERMAN, D.; ELMORE, K.; SMITH, G. Self, self-concept, and identity. Handbook of Self and Identity, 2, 69-104, 2012.

PEREZ, V.V.; PRZYBYLSKI, M. P. A relação contracultura e literatura periférica nos grupos de jovens das favelas brasileiras: diálogos possíveis. Núcleos canônicos e periféricos em diálogo com os novos media, v. 1980, p. 100.2016.

ROLLINS, R. ; DELAMERE, T. Measuring the social impact of festivals. Annals of Tourism Research, 34(3), 805-808, 2007.

SANTIAGO, P. Cidade como Utopia e a Favela como Espaço Estratégico de Inserção na Cultura Urbana (1856-1930). Revista Trajetos, v. 1, n. 2, 2016.

SCHORI, D.; HOFMANN, K.; ABEL, T. Social inequality and smoking in young Swiss men: intergenerational transmission of cultural capital and health orientation. International journal of public health, v. 59, n. 2, p. 261-270, 2014.

SHANKA, T., ALAMIYO, G. Motivations to Visit Events/Festivals: An Exploratory Investigation, in BOGOMOLOVA, S.; LEE, R., ROMANIUK, J. (ed), Australian and New Zealand Marketing Academy Conference, 2012.

VAN HOUTTE, M.; DEMANET, J.; STEVENS, P. A Selfesteem of academic and vocational students: Does withinschool tracking sharpen the difference. Acta Sociologica, 55 (1), 73-89, 2012.

VINEREAN, A. The influence of hedonic and utilitarian motivators on likelihood to buy a tourism package. Expert Journal of Marketing, 1(1), 28-37, 2013.

WU, F. The Influence of Non-mainstream Culture on the Aesthetic Judgment of Fashion Trends. Research Journal of Textile and Apparel, v. 19, n. 2, p. 42-47, 2015.

YIN, R. K. Qualitative research from start to finish. New York: The Guilford Press, 2011.

YUKI, M. Intergroup comparison versus intragroup relationships: A cross-cultural examination of social identity theory in North American and East Asian cultural contexts. Social Psychology Quarterly, 4(2), 166-183, 2003.

Artigo recebido em: $31 / 01 / 2017$

Avaliado em: 14/06/2017

Aceito em: 19/10/2017 